\title{
Questões ambientais versus economia em Sistemas de Gestão Ambiental: avanços e perspectivas
}

ISSN

1809-9475

\section{Environmental issues versus the economy in Environmental Management Systems: Progress and Prospects}

\author{
Emmanuelle Galante Roussouliéres ${ }^{1}$ \\ Priscila Araujo Lima ${ }^{1}$ \\ Rian Silva Carvalho Pires ${ }^{1}$ \\ André Barbosa Vargas ${ }^{2}$ \\ Fábio Souto Almeida ${ }^{1}$
}

Palavras-chave:

Certificação

Mercado verde

Selo verde

Sustentabilidade

\section{Artigo \\ Original}

\author{
Original \\ Paper \\ Recebido em \\ 03/2013 \\ Aprovado em \\ $08 / 2013$
}

\begin{abstract}
Resumo:
Um Sistema de Gestão Ambiental (SGA) pode ser entendido como o conjunto dos procedimentos necessários para administrar uma empresa garantindo que as suas atividades gerem o menor impacto negativo possível sobre o ambiente. As empresas que buscam produzir sem por em risco a qualidade do ambiente garantem para si um diferencial, que pode destacá-las no mercado e garantir novos consumidores. Com o SGA também se pode reduzir o custo de produção, por diminuir os gastos com insumos e gerar benefícios sociais e ambientais. Toda a sociedade se beneficia do SGA, através da qualidade ambiental que é mantida ou melhorada. Do mesmo modo, os recursos ambientais são conservados e a biodiversidade é protegida. A ISO 14000 foi criada em 1996, quando a International Organization for Standardization criou as normas de gestão ambiental de âmbito internacional. A partir de então, empresas de diversos países podem adotar as normas e certificar seus serviços e produtos. Os empresários vêm tomando consciência das vantagens da adoção de um SGA, pois o número de certificações vem aumentando em todo o mundo. Pode-se concluir que o SGA é uma ferramenta importante para as empresas que visam ganhar mercado e lucratividade, mas também para a obtenção de um ambiente ecologicamente equilibrado.
\end{abstract}

\begin{abstract}
:
An Environmental Management System (EMS) can be understood as a set of procedures for managing a company, aiming generates the least possible negative impact on the environment. Companies that seek to produce without jeopardizing the quality of the environment to guarantee itself a differential, which can highlight them on the market and secure new customers. Environmental Management Systems can reduce the cost of production by reducing spending on inputs, and generate social and environmental benefits. The society obtains benefits of EMS, through which environmental quality is maintained or improved. Similarly, environmental resources are preserved and biodiversity is protected. The ISO 14000 was established in 1996 when the International Organization for Standardization created the environmental management standards of international scope. Companies from various countries can adopt the standards and certify their products and services. Entrepreneurs are becoming aware of the advantages of adopting an EMS because the number of certifications is increasing. It can be concluded that the EMS is an important tool for companies seeking to gain market share and profitability, but also to obtain an ecologically balanced environment.
\end{abstract}

Keywords:

Certification

Green market

Green seal

Sustainability 


\section{Introdução}

Nos últimos séculos, a humanidade tem apresentado um crescimento populacional acelerado, que desencadeou uma série de problemas ambientais (CUNHA \& GUERRA, 2007). Dentre tais problemas, o esgotamento dos recursos naturais está entre os mais graves (PRIMACK \& RODRIGUES, 2001). Diante desse cenário, começou a se pensar em estratégias para um desenvolvimento com caráter mais sustentável. Este pensamento tem assumido, atualmente, destacada importância no cenário político mundial.

É provável que a definição mais conhecida de desenvolvimento sustentável seja a do Relatório Brundtland, também conhecido como "Nosso futuro comum" (1987), gerado pela Comissão Mundial das Nações Unidas para o Meio Ambiente e Desenvolvimento (SEIFFERT, 2011a). Nesse relatório o desenvolvimento sustentável é definido como o desenvolvimento capaz de satisfazer as necessidades da presente geração sem comprometer a capacidade das gerações futuras satisfazerem as suas próprias necessidades (DIEGUES, 1992). O desenvolvimento sustentável pode ainda ser entendido como o alcance de condições que propiciem a manutenção ou a recuperação dos serviços prestados pelos ecossistemas ao ser humano, em bases que possam garantir a igualdade social (ABRAMOVAY, 2010).

No campo empresarial, uma das alternativas que podem ser utilizadas para reverter o cenário atual de degradação dos recursos naturais é a utilização de práticas menos agressivas "conservacionistas". Essas precisam visar e minimizar os impactos negativos gerados na produção de bens e serviços (SEIFFERT, 2011b). Assim, potencializando os impactos positivos sem esquecer-se de fomentar e impulsionar a qualidade de vida e a igualdade social.

Desse modo, dada a importância de desenvolver-se sustentavelmente, promovendo a qualidade de vida e políticas ambientais voltadas à sociedade, foram criados alguns sistemas de gestão empresarial apoiados em normas para a conservação e preservação do meio ambiente (DONAIRE 1995). Esses sistemas consistem na gestão de usos corretos e adequados dos recursos naturais, visando a sua conservação e o desenvolvimento social
(CAMPOS, 2002). Um Sistema de Gestão Ambiental (SGA) pode ser entendido como um conjunto de procedimentos necessários para administrar uma empresa com o objetivo de garantir que suas atividades gerem o menor impacto negativo, possível, sobre o ambiente. O SGA visa também potencializar os benefícios ambientais advindos das atividades de uma empresa. Assim, o SGA pode ser uma importante ferramenta para alcançar o almejado desenvolvimento sustentável (CHRISTIE, 1995; TACHIZAWA, 2002).

O início da gestão ambiental está ligado ao momento em que o ser humano percebeu que suas atividades poderiam prejudicar o meio ambiente e provocar a escassez de recursos, o que ocorreu logo após a Revolução Industrial (DALLAS, 2009). Assim, o ser humano constatou que deveria criar mecanismos para que as suas atividades causassem menos danos aos ecossistemas naturais e se tornassem mais sustentáveis. Mediante essa necessidade, a partir do início da década de 70, diversos países criaram arcabouço jurídico-político para salvaguardar o meio ambiente e os recursos naturais, focando principalmente na questão do licenciamento ambiental (SANCHES, 2008).

Foi, principalmente, após a Conferência de Estocolmo, em 1972, que a preocupação de englobar as questões ambientais nas discussões acerca do desenvolvimento da humanidade ficou em evidência. Um dos resultados dessa conferência foi a criação da Comissão Mundial das Nações Unidas para o Meio Ambiente e Desenvolvimento, que publicou, em 1987, o relatório intitulado "Nosso futuro comum". Nesse relatório, evidencia-se, em longo prazo, a não sustentabilidade dos modelos de desenvolvimento empregados pela maioria dos países (DIEGUES, 1992).

$\mathrm{Na}$ década de 70, a postura típica era considerar antagônica a relação entre desenvolvimento e conservação dos recursos naturais, mas essa ideia foi abandonada por parte do setor industrial na década de 80 (LAYRARGUES, 2000). Nessa época, as discussões acerca da relação entre produção e proteção ambiental ficaram em evidência e soluções para conciliar essas duas questões foram surgindo. No início da década de 90 , foi realizada a Conferência das Nações Unidas sobre o Meio Ambiente e o Desenvolvimento 
(CNUMAD), também conhecida como Eco 92. Essa conferência contou com a participação de vários países e resultou na Convenção sobre Diversidade Biológica e na Agenda 21, documentos que direcionam a conservação da biodiversidade e o desenvolvimento sustentável. A Agenda 21 propõe que não só os governos, mas todos os setores da sociedade devem se comprometer com a solução dos problemas sociais e ambientais, buscando o desenvolvimento sustentável (PNUMA, 2013).

A partir do início da década de 90, a participação das empresas na busca pelo desenvolvimento sustentável se destacou na comunidade ambientalista e apresentou avanços em direção à produção industrial limpa (LAYRARGUES, 2000). Nesse sentido, as normas BSI 7750 (British Standards Institute), de origem britânica, surgiram no ano de 1992 como especificações para Sistemas de Gestão Ambiental. Em 1995, na União Europeia foi lançado outro Sistema de Gestão Ambiental e Auditoria, o Eco-Management and Auditing Scheme (EMAS). Já no ano de 1996, surgiram as normas da série ISO 14000, sendo um sistema de normas ambientais de âmbito mundial (SEBRAE, 2004). A partir de então, a certificação ambiental passou a ser almejada por diversas empresas, para que pudessem se manter competitivas em um mercado no qual os consumidores exigem cada vez mais que as organizações apresentem uma postura ambientalmente correta (MAIMON, 1999).

\section{Normas ISO 14000}

Em 1947, foi fundada a Organização Internacional para Normatização (International Organization for Standardization - ISO) (MARIANI, 2006). Com sede em Genebra na Suíça, essa organização, não governamental, já presente em 164 países (ISO, 2012a), é representada no Brasil pela Associação Brasileira de Normas Técnicas (ABNT) e $\mathrm{o}$ organismo de acreditação relacionado à ABNT é o Instituto Nacional de Metrologia, Normalização e Qualidade Industrial (INMETRO) (MARIANI, 2006).

A ISO 14000 foi criada em 1996, quando a International Organization for Standardization promulgou as normas de ges- tão ambiental (Morrow \& Rondinelli, 2002). A partir de então, empresas de diversos países podem adotar as normas, implantando Sistemas de Gestão Ambiental, e, assim, certificar seus serviços e produtos, o que é um atestado de que esses satisfazem padrões de qualidade ambiental. Isso é importante frente a mercados consumidores preocupados com os impactos ambientais gerados pela produção de bens e serviços (SEIFFERT, 2011b). Hoje, é a certificação ambiental mais conhecida em todo o mundo. Somando isso ao fato de ser aplicável em qualquer empresa, faz com que seja desejada por várias organizações.

O processo pelo qual a organização é submetida para conseguir o reconhecimento de que faz uma gestão ambientalmente correta envolve a avaliação de todo o processo produtivo através de auditorias ambientais. Questões como a identificação de aspectos ambientais e a avaliação de impactos ambientais, a análise de requisitos legais, a definição de metas ambientais de medição e monitoramento, a definição de uma política ambiental para a empresa e a realização de auditorias internas fazem parte do processo de implantação de um Sistema de Gestão Ambiental para a certificação ISO 14001 (SEIFFERT, 2011a).

\section{Os selos verdes}

A possibilidade do esgotamento de recursos naturais indispensáveis para a manutenção da vida humana é uma realidade em muitas regiões do globo terrestre. A sociedade vem tomando conhecimento dos problemas gerados pelo mau uso dos recursos naturais e tem se preocupado com os modos de produção utilizados pelas empresas e pelo passivo ambiental que é gerado durante o processo produtivo. Nessa atual conjectura, as empresas que adotam processos produtivos ambientalmente corretos podem levar vantagem sobre outras empresas, pois os consumidores que se preocupam com questões ambientais podem dar preferência aos produtos e serviços gerados de forma ambientalmente correta. Assim, a proteção do meio ambiente tornou-se uma oportunidade de mercado e as empresas que se preocupam com essa fatia da demanda podem obter vantagem competitiva (D'AVIGNON \& CARUSO, 2011). 
As organizações podem demonstrar para o consumidor que seus produtos são gerados de forma ambientalmente correta através dos selos verdes. Segundo DEUS et al. (2010), os selos verdes são rótulos inseridos nos produtos com o objetivo de demonstrar que a marca é socialmente e ambientalmente correta, além de ter a função de conscientizar o consumidor quanto ao consumo sustentável. O selo verde deve ser fornecido por uma certificadora que atesta que os produtos ou serviços de uma organização se adéquam às normas da certificadora, ou seja, são gerados de forma ambientalmente correta. Assim, os selos verdes constituem uma forma de marketing verde, que auxilia a melhorar a imagem da empresa junto aos consumidores (FIGUEIREDO et al., 2009).

O selo verde referente à ISO 14001 é só um dos vários existentes na atualidade. Um dos mais conhecidos no Brasil é o do Programa Cafés Sustentáveis do Brasil (PCS) que foi lançado em 2006. O selo é dado a empresas que produzem café e que passam por um processo de certificação que envolve questões ambientais, econômicas e sociais. Na avaliação é levado em conta o uso correto de agroquímicos, o armazenamento de fertilizantes, os cuidados com os mananciais de água, com a biodiversidade e a gestão de resíduos. As empresas também devem possuir programas de redução do uso de água, energia e papel. Além disso, as condições de trabalho oferecidas pela empresa são averiguadas (ABIC, 2013).

No campo da produção florestal pode-se destacar a certificação FSC (Forest Stewardship Council), que possibilita ao consumidor reconhecer produtos obtidos através de um correto manejo florestal, englobando produtos madeireiros e não madeireiros. O FSC foi fundado em 1993 e hoje possui representação em mais de 70 países (FSC, 2013). No Brasil, existe o Conselho Brasileiro de Manejo Florestal (FSC Brasil) que faz a Certificação de Manejo Florestal, avaliando se a floresta é manejada de forma correta, e a Certificação de Cadeia de Custódia, que garante que a madeira utilizada não foi obtida de forma ambientalmente ou socialmente nociva (FSC, 2013). Também existe o Programa Brasileiro de Certificação Florestal (Cerflor), que foi criado em 2002, e possui a ABNT como organismo que elabora as suas normas e certifica a cadeia de custódia e o manejo florestal (INMETRO, 2013).

\section{Certificados não avaliados por órgãos certificadores}

As empresas devem transparecer credibilidade frente aos consumidores. No caso dos selos verdes, as certificadoras atestam que os produtos ou serviços provêm de organizações com preocupações verdadeiras para com o meio ambiente (LAYRARGUES, 2000). Todavia, algumas empresas têm adotado a auto-certificação. Nesse caso, a produção não é avaliada por um órgão certificador independente, o que pode por em dúvida a sua validade.

Os selos verdes em produtos certificados por um órgão independente têm credibilidade. Por outro lado, a falta de transparência e de valores de referência na auto-certificação não permite que o consumidor tenha certeza do seu processo produtivo. $\mathrm{O}$ consumidor precisa crer que a empresa realiza auditorias internas e que providencia a sua própria fiscalização. Mas como saber se as organizações realmente realizam esses processos? Como ter certeza se o processo é desenvolvido de forma correta, dentro de normas ambientais rígidas?

Paira sobre esse assunto dúvidas que abrangem questões morais, mas também de mercado. As organizações que adotam os selos verdes buscam aumentar a confiança e admiração dos consumidores quanto aos seus produtos, possibilitando aumentar suas vendas. Embora os selos advindos da auto-certificação possam ajudar a alcançar esse objetivo, para a parcela de consumidores que conhecem os selos que são certificados por órgãos independentes e os que não são, a auto-certificação pode ter efeito contrário ao esperado. Assim, adotar selos avaliados por organismos certificadores conhecidos e de prestígio pode ser a melhor opção.

\section{ISO 14000 no Brasil e no mundo}

Cada vez mais os empresários tomam consciência das vantagens da adoção de um Sistema de Gestão Ambiental e buscam certificar os seus produtos ou serviços. O número de certificados ISO 14001 emitidos vem aumentando em todo o mundo, mas principalmente no Extremo Oriente e na Europa (Figura 1). Aproximadamente metade dos certificados foi emitida no Extremo 
Oriente, mas a Europa também apresenta elevado número de certificações (Figura 2). Cabe ressaltar o baixo número de certificados emitidos na América do Norte, apesar de contar com a maior economia do mundo, os Estados Unidos da América. O elevado número de certificados do Extremo Oriente se deve, principalmente, aos emitidos na China e Japão (Tabela 1). O incre- mento do número de certificações na China parece estar correlacionado com o crescimento da economia. Das sete maiores economias do mundo (Estados Unidos da América, China, Japão, Alemanha, França, Reino Unido e Brasil), somente os EUA, a França e o Brasil não aparecem entre os dez países com maior número de certificações ISO 14001.

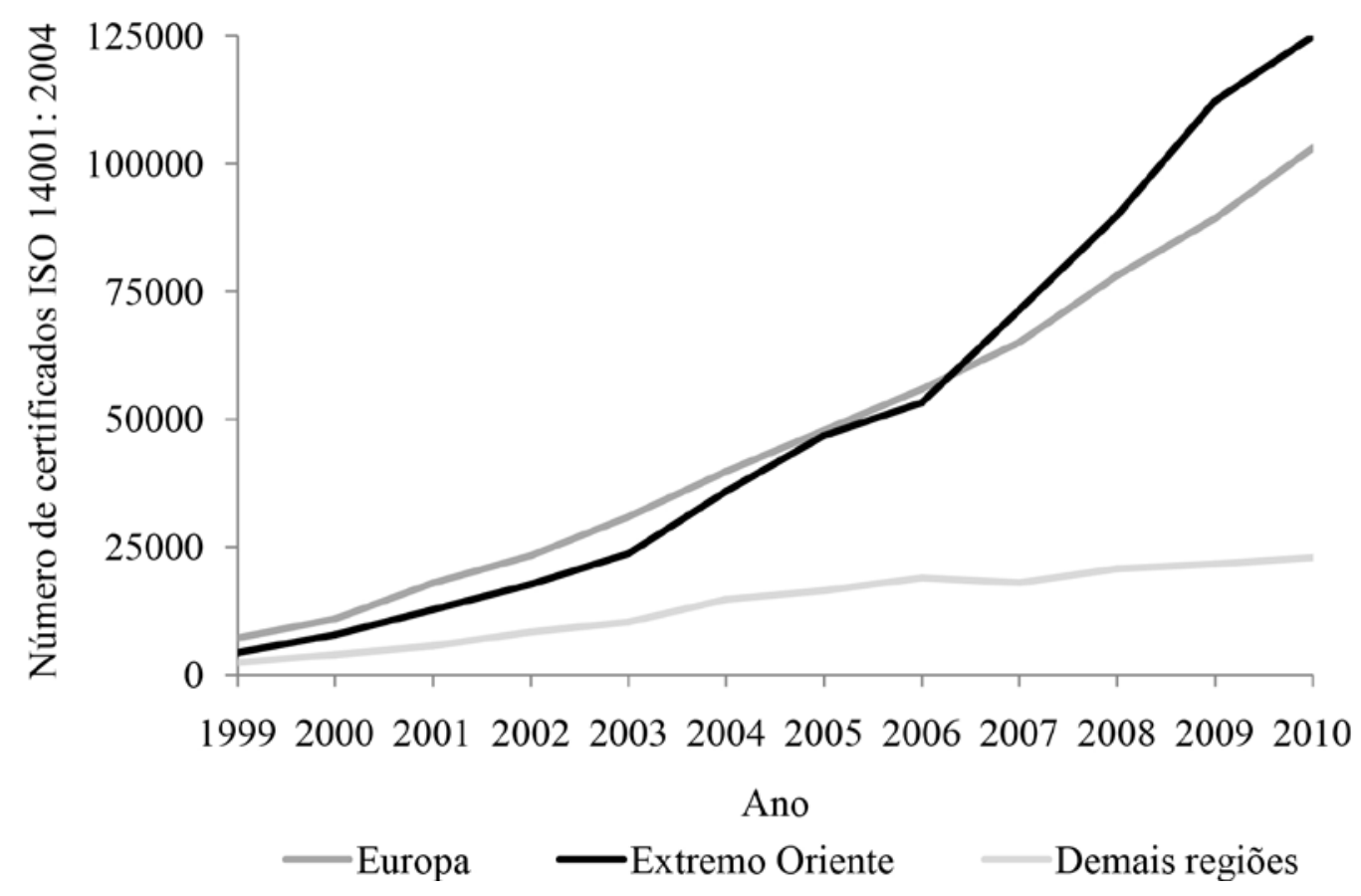

Figura 1. Número de certificados ISO 14001 emitidos de 1999 até 2010 em diferentes regiões do mundo (ISO, 2012b).

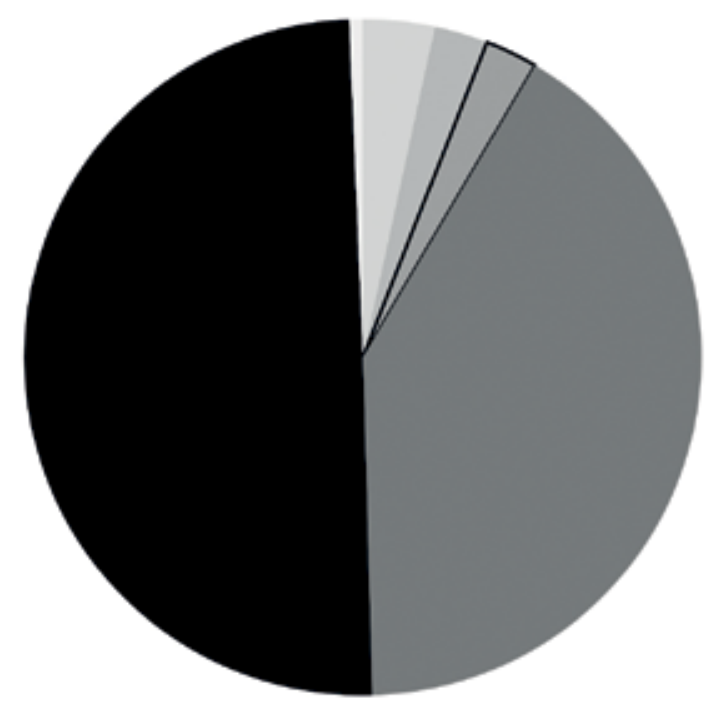

E África / Oeste da Ásia

= América Central / América do Sul

$\square$ América do Norte

- Europa

- Extremo Oriente

Austrália / Nova Zelândia

Figura 2. Porcentagem de certificados ISO 14001 emitidos de 1999 até 2010 em diferentes regiões do mundo (ISO, 2012b). 


\begin{tabular}{lll}
\hline Posição & País & $\begin{array}{l}\text { Número de } \\
\text { Certificados }\end{array}$ \\
1 & China & 69784 \\
2 & Japão & 35016 \\
3 & Espanha & 18347 \\
4 & Itália & 17064 \\
5 & Reino Unido & 14346 \\
6 & República da & 9681 \\
7 & Coréia & 7418 \\
8 & Romênia & 6629 \\
9 & República Checa & 6001 \\
10 & Alemanha & 4622
\end{tabular}

No Brasil, a grande maioria dos certificados ISO 14001 foram emitidos para organizações da região Sudeste (Figura 3). Após o Sudeste, segue-se a região Sul e o Nordeste como as regiões onde mais certificados foram emitidos, validando Sistemas de Gestão Ambiental. A vantagem da região Sudeste sobre as demais quanto ao número de certificados deve-se em grande parte ao Estado de São Paulo, que apresenta o número de certificações expressivamente maior que dos demais estados (Tabela 2), que por sua vez está relacionada à concentração de contingente populacional e de empresas. Um dado negativo é a queda do número de certificados emitidos no país de 2008 até 2012.

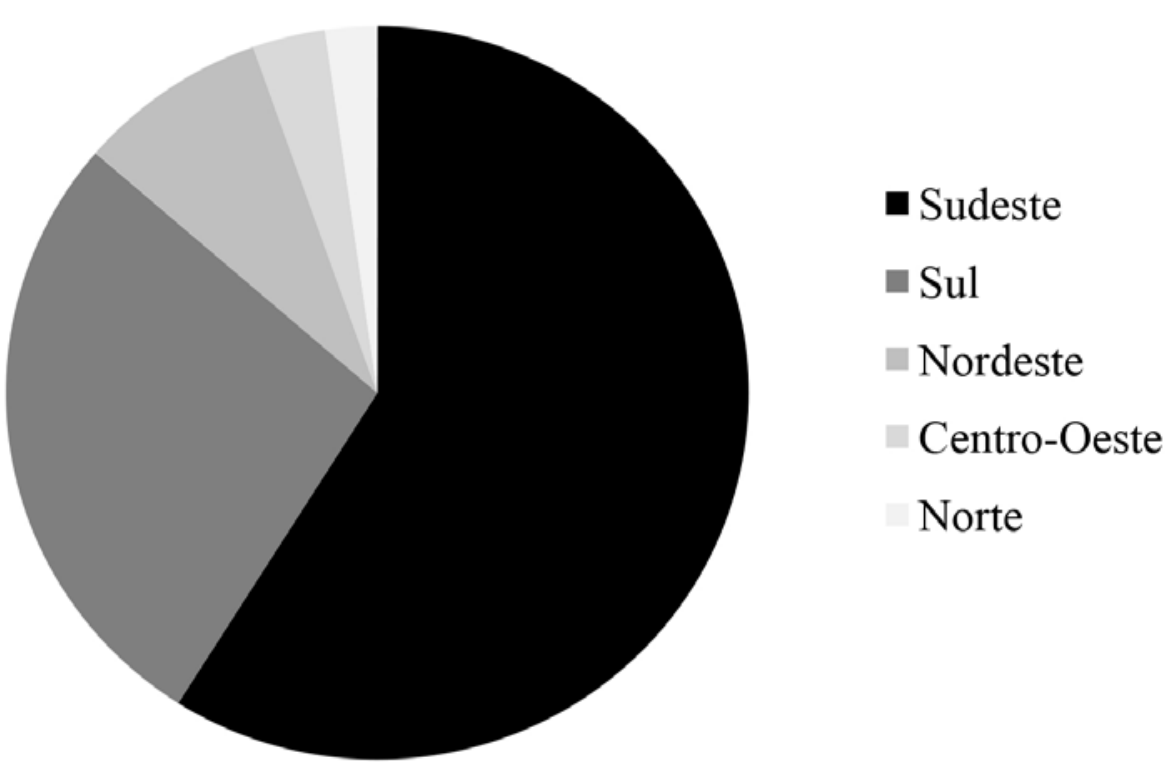

Figura 3. Porcentagem de certificados ISO 14001 emitidos de 1999 até 2010 em diferentes regiões do Brasil (Inmetro, 2012). 
Tabela 2. Número de certificados ISO 14001 emitidos de 2008 até novembro de 2012 em diferentes Estados brasileiros (Inmetro, 2012).

\begin{tabular}{|c|c|c|c|c|c|c|}
\hline Estados & 2008 & 2009 & 2010 & 2011 & 2012 & Total \\
\hline São Paulo & 81 & 79 & 48 & 40 & 20 & 268 \\
\hline Paraná & 17 & 24 & 12 & 13 & 12 & 78 \\
\hline Santa Catarina & 19 & 6 & 5 & 10 & 10 & 50 \\
\hline Rio de Janeiro & 9 & 3 & 2 & 6 & 4 & 24 \\
\hline Minas Gerais & 6 & 7 & 4 & 3 & 1 & 21 \\
\hline Bahia & 8 & 2 & 6 & 4 & 0 & 20 \\
\hline Rio Grande do Sul & 6 & 4 & 1 & 6 & 1 & 18 \\
\hline Goiás & 5 & 3 & 2 & 1 & 0 & 11 \\
\hline Amazonas & 3 & 1 & 2 & 4 & 0 & 10 \\
\hline Pernambuco & 1 & 0 & 2 & 1 & 4 & 8 \\
\hline Ceará & 0 & 2 & 1 & 2 & 1 & 6 \\
\hline Alagoas & 0 & 1 & 0 & 1 & 2 & 4 \\
\hline Mato Grosso do Sul & 0 & 1 & 1 & 0 & 2 & 4 \\
\hline Rio Grande do Norte & 1 & 1 & 0 & 1 & 1 & 4 \\
\hline Espírito Santo & 1 & 0 & 1 & 0 & 0 & 2 \\
\hline Mato Grosso & 1 & 1 & 0 & 0 & 0 & 2 \\
\hline Maranhão & 0 & 0 & 1 & 0 & 0 & 1 \\
\hline Pará & 0 & 1 & 0 & 0 & 0 & 1 \\
\hline Piauí & 1 & 0 & 0 & 0 & 0 & 1 \\
\hline Tocantins & 0 & 0 & 1 & 0 & 0 & 1 \\
\hline Total & 159 & 136 & 89 & 92 & 58 & 534 \\
\hline
\end{tabular}

\section{Vantagens e desvantagens dos Sistemas de Gestão Ambiental para as empresas}

Para prevenir ou mitigar os impactos ambientais, os Sistemas de Gestão Ambiental atuam nas diversas etapas do processo produtivo. A gestão deve englobar a escolha correta do fornecedor de matéria-prima, o processo de transformação dessa matéria-prima e o destino do produto após o uso (DARNALL et al., 2008). Deve-se buscar reduzir a quantidade de insumos e os resíduos gerados durante o processo produtivo, na utilização do produto ou no seu descarte (MELNYK et al., 2003). O Sistema de Gestão Ambiental visa ainda potencializar os benefícios ambientais advindos das atividades de uma empresa. Com o SGA pode- -se aumentar a eficiência das operações realizadas na empresa e conscientizar os funcionários acerca dos impactos ambientais das atividades (RONDINELLI \& VASTAG, 2000).

Segundo MORROW \& RONDINELLI (2002) empresas certificadas com o ISO 14001 relatam melhorias de desempenho ambiental, apontam melhorias quanto a reciclagem e reutilização de resíduos e materiais em geral, diminuição da emissão de resíduos e na conservação de energia e água. Com os cuidados tomados no SGA, as empresas se previnem contra acidentes ambientais, que podem causar danos à imagem da organização e gerar multas advindas dos órgãos ambientais públicos. Outra importante questão é que os Sistemas de Gestão Ambiental possibilitam tornar as organizações mais competitivas e ampliar sua 
posição no mercado nacional e internacional, devido a crescente procura por produtos "ecologicamente corretos" (MELNYK et al., 2003; SEBRAE, 2004). Assim, as empresas que buscam produzir sem por em risco a qualidade do ambiente garantem para si um diferencial, que pode destacá-las no mercado e garantir novos consumidores para os seus produtos (SEIFFERT, 2011a).

Além disso, com o Sistema de Gestão Ambiental pode-se reduzir o custo de produção, a médio e longo prazo, trazendo retornos financeiros. Todavia, outros benefícios também devem ser destacados, como os sociais e ambientais. Toda a sociedade se beneficia do Sistema de Gestão Ambiental implantado em uma empresa, por meio da qualidade ambiental que é mantida ou melhorada, podendo ocorrer melhorias até mesmo no âmbito da saúde pública, devido a menor quantidade de poluentes lançados no ambiente (SEIFFERT, 2011b). Do mesmo modo, por meio do Sistema de Gestão Ambiental, os recursos ambientais são conservados e a biodiversidade é protegida de impactos, como os causados pela poluição advinda do lançamento de resíduos gerados durante a produção (SEBRAE, 2004). A importância do assunto está ligada a sustentabilidade, questão amplamente discutida atualmente.

Em alguns casos, a adoção de tecnologias e comportamentos ambientalmente corretos pode ser um processo demorado, necessita de treinar os funcionários e de planejamento para cumprir as normas, fazer o monitoramento do sistema e buscar a sua melhoria contínua (SEBRAE, 2004; SEIFFERT, 2011a). Pode ocorrer até mesmo a troca de fornecedores de matéria-prima (SEBRAE, 2004). Isso pode fazer com que o custo da implantação de um SGA seja inicialmente alto e o retorno só ocorrerá de médio a longo prazo. Todavia, as empresas vêm amadurecendo a deia de que os benefícios gerados pelos SGAs para as próprias empresas e para a sociedade e a natureza suplantam as dificuldades de se manter um SGA.

\section{Considerações finais}

Os Sistemas de Gestão Ambiental surgiram como resposta à crise ambiental vivida nas últimas décadas. Foram desenvolvidos para auxiliar a reverter o quadro de perda de qualidade dos recursos naturais e colaborar para o desenvolvimento sustentável. Seu surgimento se deve ainda a necessidade das empresas de se adaptarem a um mercado consumidor consciente dos problemas ambientais. Para demonstrar aos consumidores que a empresa possui verdadeira preocupação ambiental, essas certificam seus produtos em um processo que envolve órgãos certificadores independentes e estampam em seus produtos os selos verdes. Existem várias certificações, destacando-se a ISO 14000 que pode ser aplicada a qualquer empresa e é mundialmente reconhecida. Por outro lado, alguns selos verdes são nacionais e foram elaborados para determinados produtos. Os consumidores podem confiar que produtos e serviços certificados por organismos certificadores são obtidos a partir de processos ambientalmente corretos. Entretanto, determinadas organizações adotam a auto-certificação, na qual a produção não é avaliada por um órgão certificador independente, pondo em dúvida a credibilidade da empresa e a validade do selo verde. Além disso, pode não contribuir com o objetivo básico dos Sistemas de Gestão Ambiental, que é o de contribuir para que a humanidade alcance o desenvolvimento sustentável.

$\mathrm{O}$ número de organizações que têm reconhecido os Sistemas de Gestão Ambiental como um mecanismo para o seu crescimento e um dispositivo para gerar benefícios ambientais e sociais vem crescendo em todas as partes do globo terrestre. Entretanto, apesar de ser uma das maiores economias do mundo e se apresentar como um dos países com as maiores reservas de diversos recursos naturais e biodiversidade, o Brasil não está entre os países com maior número de certificações ISO 14000. Devido a problemas sociais e econômicos históricos, o Brasil dá prioridade ao desenvolvimento econômico, em detrimento da conservação ambiental, acreditando-se que os impactos ambientais decorrentes desse desenvolvimento são aceitáveis (ROHRICH \& CUNHA, 2004). Entretanto, esse quadro deve ser revertido para que o país possa se desenvolver de forma sustentável.

Por meio dos Sistemas de Gestão Ambiental as organizações economizam insumos, melhoram a sua imagem frentes aos 
consumidores e se previnem contra acidentes ambientais. Todavia, os benefícios gerados pelos Sistemas de Gestão Ambiental não trazem vantagens apenas para as empresas, mas para toda a sociedade. Pode-se concluir que o SGA é uma ferramenta importante para as empresas que visam ganhar mercado e lucratividade, mas também para a obtenção um meio ambiente ecologicamente equilibrado, gerando benefícios sociais.

\section{Referências Bibliográficas}

1. ABIC - Associação Brasileira da Indústria de Café. Disponível em <http:// www.abic.com.br/publique/cgi/cgilua. exe/sys/start.htm?sid=16>. Acesso em: 18.fev. 2013.

2. ABRAMOVAY, R. Desenvolvimento sustentável: qual a estratégia para o Brasil? Novos Estudos, v.87, p.97-113, 2010.

3. CHRISTIE, I.; ROLFE, H.; LEGARD, $\mathrm{R}$. Cleaner production in industry: integrating business goals and environmental management. London: Policy Studies Institute, 1995.

4. CUNHA, S. B.; GUERRA, A. J. T. Avaliação e perícia ambiental. 8 ed. Rio de Janeiro: Bertrand Brasil. 2007. 294p.

5. DALLAS, N. Como tornar sua empresa ecologicamente responsável: 24 lições para superar os desafios do aquecimento global, Rio de Janeiro, Sextante, 2009.

6. DARNAL, N.; JOLLEY, G. J.; HANDFIELD, R. Environmental Management Systems and Green Supply Chain Management: complements for sustainability? Business Strategy and the Environment, v.18, p.30-45, 2008.

7. D'AVIGNON, A.; CARUSO, L. A. C. O caráter necessariamente sistêmico da transição rumo à economia verde. Política Ambiental, Belo Horizonte, n. 8, p. 24-35, jun. 2011. Disponível em: $<$ http://www.conservation.org. br/publicacoes/files/politica_ambiental_08_ portugues. pdf $>$. Acesso em: 27 fev. 2013.
8. DEUS, N. S.; FELIZOLA, M. P. M.; SILVA, C. E. O consumidor socioambiental e seu comportamento frente aos selos de produtos responsáveis. Revista Brasileira de Administração Científica, v.1, n.1, p.32 $\square 54,2010$.

9. DIEGUES, A. C. Desenvolvimento sustentável ou sociedades sustentáveis: da crítica dos modelos aos novos paradigmas. São Paulo em Perspectiva, v.6, p.22-29, 1992.

10. DONAIRE, D. Gestão ambiental na empresa, São Paulo: Ed. Atlas, 1995.

11. FIGUEIREDO, G. N.; ABREU, R. L.; CASAS, A. L. L. Reflexos do índice de sustentabilidade empresarial (ISE) na imagem das empresas: uma análise do consumidor consciente e do marketing ambiental. Pensamento \& Realidade, v.24, n.1, p.107-128, 2009.

12. FSC - Forest Stewardship Council. Disponível em <http:// http://br.fsc.org/>. Acesso em: 18.fev.2013.

13. Inmetro - Instituto Nacional de Metrologia, Qualidade e Tecnologia. Disponível em $<$ http://www.inmetro.gov. br/gestao14001/dados_estat.asp?Cham ador=INMETRO14\&tipo $=$ INMETROE XT>. Acesso em: 15.nov.2012.

14. Inmetro - Instituto Nacional de Metrologia, Qualidade e Tecnologia. Disponível em $<$ http://www.inmetro.gov.br/qualidade/ cerflor.asp>. Acesso em: 18.fev.2013.

15. ISO - International Organization for Standardization. Disponível em $<\mathrm{http}$ // www.iso.org/iso/ about/iso members. htm>. Acesso em: 13.set.2012 a.

16. ISO - International Organization for Standardization. Disponível em $<\mathrm{http}$ :/ www.iso.org/iso- survey2010.pdf.>. Acesso em: 15.nov.2012 b. 
17. LAYRARGUES, P. P. Sistemas de gerenciamento ambiental, tecnologia limpa e consumidor verde: a delicada relação empresa-meio ambiente no ecocapitalismo. Revista de Administração de Empresas, v.40, p.80-88, 2000.

18. MAIMON, D. ISO 14001 - Passo a Passo da Implantação nas Pequenas e Médias Empresas. Rio de Janeiro: Qualitymark Editora Ltda., 1999.

19. MARIANI, E. J. As normas ISO. Revista Científica Eletrônica de Administração, v.6, n.10, 2006. Disponível em <http:// www.revista.inf.br/adm11/pages/artigos/ ADM-edic10-anovi-art03.pdf>. Acesso em: 13.set.2012.

20. MELNYK, S. A.; SROUFE, R. P.; CALANTONE, R. Assessing the impact of environmental management systems on corporate and environmental performance. Journal of Operations Management, v.21, p. 329-351, 2003.

21. MORROW, D.; RONDINELLI, D. Adopting corporate Environmental Management Systems: motivations and results of ISO 14001 and EMAS certification. European Management Journal, v.20, n.2, p.159-171, 2002.

22. PNUMA. Rumo a uma economia verde: caminhos para o desenvolvimento sustentável e a erradicação da pobreza - uma síntese para tomadores de decisão. Brasília, 2011. Disponível em: $<$ http://www.pnuma.org.br/arquivos/ EconomiaVerde_ResumodasConclusoes. pdf $>$. Acesso em: 27 fev. 2013.
23. PRIMACK, R. B.; RODRIGUES, E. Biologia da Conservação. Londrina: Editora Planta. 2001. 328p.

24. ROHRICH, S. S.; CUNHA, J. C. A proposição de uma taxonomia para análise da Gestão Ambiental no Brasil. Revista de Administração Contemporânea, v.8, n.4, p. 81-97, 2004.

25. RONDINELLI, D.; VASTAG, G. Panacea, common sense, or just a label? The value of ISO 14001 Environmental Management Systems. European Management Journal, v.18, n.5, p.499510, 2000.

26. SANCHEZ, L. A. Avaliação de impacto ambiental: conceitos e métodos. São Paulo: Oficina do Textos, 2008. 495p.

27. SEBRAE - Serviço Brasileiro de Apoio às Micro e Pequenas Empresas. Curso Básico de Gestão Ambiental. Brasília: Sebrae, 2004. 111p.

28. SEIFFERT, M. E. B. ISO 14001 Sistemas de Gestão Ambiental: Implantação objetiva e econômica. São Paulo: Editora Atlas, 2011a. 239p.

29. SEIFFERT, M. E. B. Sistemas de Gestão Ambiental (SGA-ISO 14001): melhoria contínua e produção mais limpa na prática e experiência de 24 empresas brasileiras. São Paulo: Editora Atlas, 2011b. 156p.

30. TACHIZAWA, T. Gestão ambiental e responsabilidade social corporativa: estratégias de negócios focadas na realidade brasileira. São Paulo: Ed. Atlas, 2002. 